\title{
Consumer desires and perceptions of lactose-free milk
}

P. V. Rizzo, W. S. Harwood, and M. A. Drake* (i)

Department of Food, Bioprocessing, and Nutrition Sciences, Southeast Dairy Foods Research Center, North Carolina State University, Raleigh 27695

\section{ABSTRACT}

Fluid milk consumption has declined in the United States, but lactose-free dairy milk (LFM) sales have steadily increased. It is important to understand how consumers perceive LFM and what consumers value when purchasing LFM. This study characterized consumer perceptions and preferences for LFM. Three 1.5$\mathrm{h}$ focus groups $(\mathrm{n}=25)$, an online survey $(\mathrm{n}=331)$, trained panel descriptive analysis, and a consumer acceptance taste test $(\mathrm{n}=160)$ were conducted with LFM consumers. Focus groups were evaluated by frequency of responses. From the focus group findings, we found that price was a primary choice driver of LFM. Habit and flavor familiarity with cow milk were a major driver of selection of LFM over plant-based alternatives for consumers. Higher sweetness and lower viscosity were the primary sensory differences between LFM and traditional milk, and were viewed negatively in general. The online survey included Kano questions, maximum difference scaling, and an adaptive choice-based conjoint. The data gathered from these techniques provided insight into the perceptions and purchase habits of consumers. Kano data demonstrated consumer attitudes toward the presence or absence of product attributes. The maximum difference scaling scaled the importance of product attributes to consumers. An adaptive choice-based conjoint provided insight into consumer purchase habits by simulating a purchase decision through an online interface. The attributes evaluated included price, packaging material, package size, lactose removal method, shelf life, sweetness, texture, nutrition claims, and label claims. Survey responses were analyzed by univariate and multivariate statistics. Survey results quantitatively confirmed many focus group observations. Price, texture, sweetness, shelf life, and package size were the most important attributes to LFM consumers. A low price, ultrapasteurized LFM in a half-gallon cardboard package was the ideal LFM.

Received November 21, 2019

Accepted March 22, 2020.

*Corresponding author: maryanne_drake@ncsu.edu
Descriptive analysis of 9 commercial LFM followed by consumer acceptance testing was conducted. External preference mapping was conducted with trained panel and consumer acceptance results. Consumer acceptance testing of commercial LFM revealed 3 consumer clusters with distinct preferences for LFM flavor and texture. High sweet taste was a driver of liking for the overall population, and eggy flavor and viscosity were drivers of disliking. Knowledge of consumer preferences for LFM will provide actionable insights for new product development within the dairy industry for this market segment.

Key words: lactose-free milk, focus group, conjoint analysis, descriptive analysis, consumer acceptance

\section{INTRODUCTION}

Fluid milk sales have decreased in the United States by $3.7 \%$ from 2017 to 2018 (Dairy Management Inc., 2018). According to the United States Department of Agriculture, the total production weight of all fluid milk beverages decreased by nearly 10\% from 1987 to 2018 (USDA, 2019). Although many factors have led to this decline, such as a higher frequency of animal rights activism and vegan diets, one of the largest reasons that consumers avoid dairy is an increase in the diagnosis or perception of lactose intolerance in developed nations (Zingone et al., 2017). It is estimated that more than $70 \%$ of the world's population has some degree of lactose intolerance (Messia et al., 2007). At over 146 million gallons, lactose-free dairy milk (LFM) currently accounts for $4.0 \%$ of the total volume of fluid dairy milk sold in the United States per year, and sales are increasing. Sales of LFM grew by $12 \%$ in 2017, with an additional 9\% increase in 2018 (Dairy Management Inc., 2018). Although LFM is rising in popularity among consumers, there is little published research on LFM in general, and even less concerning its consumer preferences and purchase habits. In light of the swift rise in the popularity of LFM, it is important to understand consumer desires and perceptions surrounding it to support the dairy industry in providing LFM products that meet the needs of consumers. 
Adhikari et al. (2010) conducted a consumer study on LFM to determine consumer acceptability of LFM compared with traditional milk. That study compared the sensory characteristics of LFM at different fat contents with the corresponding traditional milks using a trained descriptive analysis panel and consumer liking. Lactose-free milk had a more intense sweet taste than traditional milk. In both traditional milk and LFM, consumer liking and fat content of the milk were directly related; as fat content of the milk increased, consumer liking scores also increased (Adhikari et al., 2010). However, a full profile of consumer expectations and perception of LFM was not conducted. Most notably, consumers were not screened to be LFM consumers, but were general milk consumers. The LFM consumer's purchase habits and preferences, such as packaging, pricing, and labeling, were not investigated. These product attributes heavily affect product success in the marketplace (McLean et al., 2017; Harwood and Drake, 2018). Additionally, the objective of that study was to compare the sensory properties of LFM and traditional milk, rather than to investigate the specific sensory properties of LFM that lead to consumer acceptance.

While Adhikari et al. (2010) is the only LFM consumer study to our knowledge, several studies involving LFM have focused on the activity of $\beta$-galactosidase in milk, as well as its chemical effects on the quality of the milk. Nielsen et al. (2018) measured the proteolytic side-activity of $\beta$-galactosidase in UHT pasteurized LFM compared with unhydrolyzed UHT milk, and found higher levels of free AA in the lactose-hydrolyzed sample, which indicated that $\beta$-galactosidase exhibited proteolytic activity in milk and can lead to a decreased product shelf life (Nielsen et al., 2018). Jansson et al. (2014) conducted a similar study with UHT lactosehydrolyzed and unhydrolyzed milk, but the study was conducted over a 9-mo storage time. They also found $\beta$-galactosidase to exhibit signs of proteolysis. Additionally, they observed higher concentrations of furosine and 2-methylbutanal in the lactose-hydrolyzed samples, indicating these samples were more prone to Maillard and other reactions involving sugars (Jansson et al., 2014). Messia et al. (2007) conducted a study focused on measuring Maillard products, such as furosine and lactulose, in lactose-hydrolyzed milk and unhydrolyzed milk. Over time, the concentration of furosine was significantly higher in lactose-hydrolyzed milk compared with traditional milk, with the opposite effect for lactulose. A higher concentration of furosine, which is a heat load indicator, suggests that lactose-hydrolyzed milk is more prone to Maillard reactions than traditional milk. Therefore, lactose-hydrolyzed milk may contain Maillard reaction flavors (such as higher cooked or caramelized flavors) not present in traditional milk with the same heat load. Messia et al. (2007) concluded that lactose-hydrolyzed milk was less chemically stable than traditional milk, given the greater reactivity of glucose and galactose compared with lactose.

Focus groups represent a popular qualitative data collection method that allows researchers to quickly learn consumer attitudes. Focus groups provide the opportunity to ask open-ended questions to gain useful insights into consumer perceptions. The process encourages the participants to determine the importance of product attributes using their own words and thoughts, enhancing an understanding of consumer perspectives (Kitzinger, 1995). Focus groups also allow participants to interact with each other in open discussions that lead to information that a researcher might not have considered.

In addition to understanding consumer perception of LFM through focus groups, it is also important to identify consumer desires that influence purchase decisions. Conjoint analysis is an analytical technique that simulates this scenario (Orme, 2010). In contrast to the qualitative nature of focus groups, conjoint analysis is a quantitative technique and is often applied to data gathered from an online survey exercise. During a conjoint survey exercise, consumers are presented with hypothetical product concepts randomly generated by the software. Survey participants are requested to choose which hypothetical product concept is most appealing. By having consumers evaluate various product attributes within product concepts, the importance of each product attribute can be assessed. Although there are many different types of conjoint analyses, adaptive choice-based conjoint (ACBC), a variant of traditional choice-based conjoint, has gained popularity and been used in studies both inside and outside of the food industry (Oltman et al., 2014; Al-Omari et al., 2017; Harwood and Drake, 2018). The ACBC surveys adapt to the specific responses of each individual, creating a personalized survey for each participant (Orme, 2010; Jervis et al., 2012). For this reason, ACBC surveys can achieve consistent data with fewer overall participants than choice-based conjoint. Furthermore, ACBC surveys are more reliable when price is included as an attribute (Chapman et al., 2009; Jervis et al., 2012; Harwood and Drake, 2018). Adaptive choice-based conjoint techniques have been applied to many food products including bread, bacon, and fluid milk (Jervis et al., 2014; McLean et al., 2017; Harwood and Drake, 2018).

Conjoint analysis survey designs are often paired with other survey methods, including maximum difference (MaxDiff) scaling and Kano questions. The MaxDiff method is similar to conjoint analysis in that it requires participants to make trade-offs, but the trade-offs are based on single attributes or statements, rather than 
entire product builds. The MaxDiff exercises do not include product concepts with multiple attributes. Consumers are presented with a list of product attributes and are asked to choose the "best" and "worst" options in the list, rather than an ideal or acceptable multi-attribute concept, similar to ACBC. Kano questions are also now fielded via an online survey interface and differ from MaxDiff and ACBC by integrating both qualitative and quantitative data. Kano questions aim to identify consumer attitudes toward certain product attributes based on whether the attribute is present or absent from a product offering (Kano et al., 1984; Zacarias, 2015). Both Kano questions and MaxDiff have been used in a variety of food studies, including chocolate milk, tomatoes, hot beverages, bacon, and fluid milk (Kim et al., 2013; Li et al., 2014; Oltman et al., 2014; McLean et al., 2017; Harwood and Drake, 2018).

While focus groups and survey methods are conceptual exercises, consumer acceptance taste tests require consumers to directly interact with the product. Blinded consumer acceptance tests have been shown to accurately assess consumer liking of foods. In conjunction with trained descriptive analysis data, consumer acceptance data can be used for preference mapping, which provides an understanding of objective sensory attributes that drive liking or disliking (Clark, 1998). To our knowledge, a collective examination of the LFM consumer has never been attempted before this study. Because the popularity of LFM is growing quickly in the United States, identifying drivers of liking and purchase habits will be extremely valuable for new product development of lactose-free beverages in the dairy industry. The goal of this study was to apply focus groups, survey methods, and consumer acceptance tests to investigate consumer desires and perceptions of LFM.

\section{MATERIALS AND METHODS}

\section{Experimental Overview}

Three focus groups were conducted to identify consumer perceptions of LFM. We conducted the focus groups first to take advantage of unexpected information that is often gathered through open discussions with consumers. This qualitative exercise was necessary for a deeper understanding of LFM consumer perceptions to assist with development of the subsequent survey and consumer liking test ballot. The online survey was conducted following the focus groups. The online survey consisted of an ACBC exercise, a MaxDiff exercise, and Kano questions. The objective of the online survey was to expand on the information obtained from the focus groups with a quantitative method. It also provided a means to reach many more consumers than would have been possible with focus groups. Additionally, it allowed for a quantitative analysis of the purchase habits and preferences of LFM consumers. Subsequently, 9 commercial 2\% LFM products (LFM1 to LFM9) were evaluated by a trained descriptive analysis (DA) panel. Finally, LFM consumers evaluated the same 9 LFM products across a 2-d period. Trained panel DA and consumer acceptance testing of LFM were separate analyses from the focus groups and online survey, and allowed for an understanding of LFM consumer preferences regarding actual sensory perception of commercially available LFM. External preference mapping was then applied with trained panel DA consumer acceptance data to illustrate the sensory properties in LFM that drive liking and disliking among consumers. All sensory and survey testing procedures were conducted in compliance with the North Carolina State University (NCSU) Institutional Review Board regulations.

\section{Focus Groups}

Three 90-min focus groups were conducted on the NCSU campus. Each focus group comprised 7 to 10 adult LFM consumers $(\mathrm{n}=25$ total). All focus group participants were between the ages of 18 and $64 \mathrm{yr}$ and consisted of 9 men and 16 women. Participants were recruited using a database of over 10,000 consumers maintained by the Sensory Service Center at NCSU. To qualify for the focus groups, consumers had to be between the ages of 18 and $64 \mathrm{yr}$, earn an annual salary greater than $\$ 20,000$, and purchase and consume LFM regularly (at least once per month). The focus groups were led by an experienced moderator, while a scribe observed remotely through video and audio online streaming. All focus group sessions were also video recorded for repeat-viewing purposes. During each focus group, the participants were asked a series of questions regarding the following focus areas: (1) Purchase Habits, (2) Packaging and Labeling, (3) Milk Processing, (4) Sensory Characteristics, (5) Milk Applications (Figure 1). All questions and responses were verbal in an open discussion format. For the Milk Processing focus area, questions were asked regarding participant knowledge of this subject. Then, participants were given an information sheet outlining pasteurization and ultrapasteurization processes, and then asked if their perception changed after being educated on the subject. The data gathered from the focus groups were used to generate the online survey. Participants were compensated with a $\$ 35$ gift card to a local store following participation in one of the focus groups. 


\section{Online Survey}

An online survey was created based on the focus group results using Lighthouse Studio (Sawtooth Software version 9.5.3, Orem, UT). The survey was fielded using the same database used for focus group participant recruitment. Consumers over the age of 18 y who had purchased and consumed LFM within the last 6 mo $(\mathrm{n}=331)$ were able to participate in the survey. After answering preliminary screen questions, participants ( 55 men and 276 women) were directed to MaxDiff scaling, Kano questions, and an ACBC survey specifically focusing on LFM. Upon full completion of the survey, participants were entered into a drawing

\section{Moderator Guide for Lactose-free Milk}

Focus Area 1: Purchase Habits

- Why do you purchase LFM? For whom do you purchase it?

- Do you also purchase traditional milk?

- Why do you purchase dairy LFM instead of plant-based milk?

- Which brands of LFM do you purchase? Are there differences between brands?

- Which fat percentage of LFM do you buy?

- How does the price of LFM compare to that of regular milk?

Focus Area 2: Packaging and Labeling

- What kind of LFM package do you most prefer (material, size)?

- Which LFM packaging elements are most important to you? Color? Picture? "Lactosefree" label?

- Are there any label claims that you would like to see on a package of LFM? (probe for: organic, rBST-free, high protein, high calcium, etc.)

Focus Area 3: Milk Processing

- How does the processing of LFM compare to that of traditional milk?

- Do you know how lactose is removed from LFM?

- What is pasteurization? What is ultrapasteurization?

- (Pasteurization/Ultrapasteurization explanation handout is given to the participants) Now that you know more about pasteurization and ultrapasteurization, has your perception of these processes changed? Positively or negatively?

Focus Area 4: Sensory Characteristics

- Are there differences between LFM and traditional milk?

- Do you want LFM to taste the same as traditional milk?

- How do different brands compare with one another?

- Is LFM natural? Is it more or less natural than traditional milk?

Focus Area 5: Milk Applications

- Do you purchase LFM for drinking only, or also for use in recipes?

- How versatile is LFM in cooking?

- Can it be used as a direct replacement for traditional milk in recipes?

- Do you think cooking with LFM affects any recipes you use it in?

Figure 1. Focus group moderator guide for lactose-free milk (LFM). 
for gift cards to a local store in the amounts of $\$ 100$ (1 total), $\$ 40$ (2 total), and $\$ 20$ (11 total).

The ACBC survey consisted of 9 attributes with 2 to 5 levels per attribute (Table 1). Prices were based on LFM prices in the Raleigh-Durham, North Carolina, area. The survey contained 1 build-your-own (BYO) task and 8 screening tasks with 4 product concepts per task. For each screening task, consumers were asked to choose which of the products presented were "a possibility" or "won't work for me." To ensure the exercise adapted to each survey participant, 5 unacceptable and 4 must-have questions were integrated into the screening portion, in compliance with the software recommendations (Orme, 2009). Subsequently, a 10-question choice task tournament section was conducted. Each choice task presented 3 randomly generated LFM product concepts based on the levels and attributes specified in Table 1. The levels within each attribute of the product concepts differed from the participant's BYO product by 2 to 4 attributes. Consumers were asked to choose the "best option" of the 3 product concepts. Twenty was the maximum number of product concepts that could be entered into the tournament. The ACBC exercise concluded after 10 choice tasks.

Preceding the ACBC exercise, consumers participated in MaxDiff scaling and Kano questions. The MaxDiff exercise consisted of 15 LFM attributes and 11 questions with 5 attributes listed per question. Consumers were asked to choose the most important and least important attribute in each set. Kano questions were asked immediately after the MaxDiff scaling exercise. They comprised many of the same features as the ACBC survey, such as questions concerning packaging, flavor, texture, and claims. Consumers were asked all Kano questions in a functional manner (e.g., "LFM that has the same sweetness as regular milk") and in a dysfunctional manner (e.g., "LFM that does not have the same sweetness as regular milk"). The response options for each LFM attribute were: "I like it," "I expect it," "I don't care/neutral," "I can live with it," and "I dislike it."

\section{Descriptive Analysis}

Nine representative commercial $2 \%$ LFM products were evaluated by a trained sensory panel. The LFM were purchased on 2 different occasions, 3 wk apart. All LFM were ultrapasteurized. The trained panel consisted of 5 women and 2 men (ages 24-54 yr), each with over $100 \mathrm{~h}$ of experience with sensory evaluation of dairy products. Panelists documented sensory attributes of LFM using a 0 to 15 point universal scale consistent with the Spectrum method (Meilgaard et al., 2007) and an established lexicon for milk (Lee et al., 2017; McCarthy et al., 2017a). Milks were evaluated at $20^{\circ} \mathrm{C}$ in coded $60-\mathrm{mL}$ soufflé cups (PFS Sales Co., Raleigh, NC). The samples were prepared with the overhead lights off to avoid light oxidation. For each of the 2 sessions, panelists were calibrated with a commercial $2 \%$ ultrapasteurized milk and a commercial $2 \%$ ultrapasteurized LFM. Panelists expectorated samples after each evaluation and rinsed with deionized water. Each milk was evaluated by each panelist in duplicate. Paper ballots were used for data collection.

\section{Consumer Acceptance Taste Test}

Subsequently, LFM consumers $(\mathrm{n}=160)$ were recruited to evaluate the nine $2 \%$ LFM evaluated by the trained panel. Consumers consisted of 46 men and 114

Table 1. Attributes and levels used in adaptive choice-based conjoint (ACBC) survey on lactose-free milk

\begin{tabular}{|c|c|c|c|c|c|c|c|c|}
\hline Price & $\begin{array}{l}\text { Package } \\
\text { material }\end{array}$ & $\begin{array}{l}\text { Package } \\
\text { size }\end{array}$ & $\begin{array}{l}\text { Lactose } \\
\text { removal } \\
\text { method }\end{array}$ & Shelf life ${ }^{1}$ & Sweetness $^{2}$ & Texture $^{3}$ & $\begin{array}{l}\text { Nutrition } \\
\text { claims }\end{array}$ & $\begin{array}{l}\text { Label } \\
\text { claims }\end{array}$ \\
\hline$\$ 2.00 / 0.5 \mathrm{gal}$ & Cardboard & Pint & Lactase enzyme & $\begin{array}{l}\text { Conventional } \\
\text { pasteurization }\end{array}$ & Less sweet & Thinner & $\begin{array}{l}\text { High } \\
\text { protein }\end{array}$ & Organic \\
\hline$\$ 3.00 / 0.5 \mathrm{gal}$ & Clear plastic & Quart & $\begin{array}{l}\text { Filtration and } \\
\text { ultrafiltration }\end{array}$ & Ultrapasteurization & $\begin{array}{l}\text { Same } \\
\text { sweetness }\end{array}$ & Same & $\begin{array}{l}\text { High } \\
\text { calcium }\end{array}$ & $\begin{array}{l}\text { Low carbon } \\
\text { footprint }\end{array}$ \\
\hline$\$ 4.00 / 0.5$ gal & $\begin{array}{l}\text { Opaque } \\
\text { plastic }\end{array}$ & $\begin{array}{l}\text { Half- } \\
\text { gallon }\end{array}$ & & Shelf stable & More sweet & Thicker & $\begin{array}{l}\text { Reduced } \\
\text { sugar }\end{array}$ & $\begin{array}{l}\text { Ethically } \\
\text { sourced }\end{array}$ \\
\hline$\$ 5.00 / 0.5 \mathrm{gal}$ & & Gallon & & & & & None & Grass fed \\
\hline$\$ 6.00 / 0.5 \mathrm{gal}$ & & & & & & & & None \\
\hline
\end{tabular}

${ }^{1}$ Conventional pasteurization $=20 \mathrm{~d}$ under refrigeration; ultrapasteurization $=60 \mathrm{~d}$ under refrigeration; shelf stable $=9$ mo without refrigeration.

${ }^{2}$ Sweetness compared with regular dairy milk.

${ }^{3}$ Texture compared with regular dairy milk. 
women who were 18 to 64 yr old, primary shoppers, and purchased and consumed LFM at least once per month. Each consumer evaluated all 9 LFM samples over a 2-d period. Five LFM were evaluated on the first day and 4 on the second day. The order of presentation for all LFM was balanced and randomized over the 2 -d period, meaning each consumer could receive any 5 of the 9 LFM on $\mathrm{d} 1$, and the remaining 4 on $\mathrm{d} 2$, in a randomized and balanced order. Consumers were served $60 \mathrm{~mL}$ of each sample in 155 -mL clear plastic tumbler (PFS Sales Co.) at $4^{\circ}$ C. Samples were coded with 3-digit blinding codes.

Before tasting, participants were first asked to look at the sample and answer questions concerning: appearance liking, color liking, and aroma liking. Justabout-right (JAR) questions for color and aroma were asked alongside their corresponding liking questions. Next, consumers were instructed to taste the LFM and asked questions concerning overall liking, flavor liking, sweetness liking, thickness/mouthfeel/viscosity liking, and aftertaste liking. The aftertaste liking question was only asked of those who indicated that they perceived an aftertaste. The JAR questions for flavor, sweet taste, cooked flavor, thickness/mouthfeel/viscosity, and creaminess were asked alongside their corresponding liking questions. Liking questions were scored on a 9 -point hedonic scale where $1=$ dislike extremely and $9=$ like extremely. The JAR questions were asked on a 5 -point scale where $1=$ much too little, $2=$ too little, $3=$ just about right, $4=$ too much, and $5=$ much too much. For each sample, quality and purchase intent questions were asked on a 5-point intensity scale. For the quality question, 1 = extremely low quality, $2=$ low quality, $3=$ neither high nor low quality, 4 $=$ high quality, and $5=$ extremely high quality. For the purchase intent question, $1=$ definitely would not buy, $2=$ probably would not buy, $3=$ might or might not buy, $4=$ probably would buy, and $5=$ definitely would buy. Consumers were instructed to cleanse their palates with deionized water and a bite of unsalted cracker between samples, and a 2-min rest was enforced between samples. Compusense Cloud (Guelph, ON, Canada) was used to collect data. All consumers were compensated with a $\$ 30$ gift card to a local store upon full completion of the consumer acceptance test.

\section{Statistical Analysis}

Online Survey. In the online survey, individual utility scores from the ACBC survey and the MaxDiff exercise were determined using hierarchical Bayesian estimation. Cluster analysis of individual utility scores from the ACBC survey was conducted with XLSTAT (version 19.5.2018, Addinsoft, Paris, France) using $k$-means clustering. Mean values of utility scores, importance scores, and MaxDiff scores were analyzed for significant differences by a one-way ANOVA with Fisher's least significant difference post hoc test at $95 \%$ confidence. Kano questions were analyzed according to the model proposed by Kano et al. (1984). The LFM attributes were assigned to Kano classifications: attractive (usually unexpected by the consumer and result in an increase in satisfaction when present); must-have (expected by the consumer and result in dissatisfaction if not present); one-dimensional (linear relationship between attribute presence and consumer satisfaction); rejecter (consumers are indifferent if the feature is absent and dissatisfied if it is present); and indifferent (consumer satisfaction is not affected by whether the feature is present or absent). The MaxDiff and Kano data were analyzed using the same clusters determined by the ACBC utility score cluster analysis to further define each consumer group.

Descriptive Analysis. Descriptive analysis data were evaluated by one-way ANOVA with Fisher's least significant difference means separation. The DA data were also analyzed using principal component analysis with XLSTAT.

Consumer Acceptance Test. In the consumer acceptance test, all 9-point liking questions were analyzed using a one-way ANOVA with Fisher's least significant difference post hoc test and means separation at $95 \%$ confidence. The JAR questions were subjected to penalty analysis at a 20\% threshold, and differences in selection proportion were determined via Chi-squared test $(\alpha=0.05)$. Quality and purchase intent questions were analyzed using Kruskal-Wallis with Dunn's post hoc test $(\alpha=0.05)$. Partial least squares regression was used for external preference mapping and was conducted with trained panel mean scores and consumer acceptance overall liking scores for the overall population and each consumer cluster. All statistical analyses were conducted using XLSTAT.

\section{RESULTS AND DISCUSSION}

\section{Focus Groups}

Each focus group began by asking participants about their purchase habits of LFM. For the majority of participants, they first began purchasing LFM after they, or a member of their family, were diagnosed with lactose intolerance. For about half of the participants, if one member of the family required LFM, the entire household consumed LFM exclusively. The remaining participants continued to purchase traditional milk in addition to LFM. Another major driver of purchase was the familiarity of dairy milk. Growing up drink- 
ing dairy milk and knowing its nutritional benefits led participants to purchase LFM instead of lactose-free plant-based alternatives. This is consistent with the results of a previous study by McCarthy et al. (2017b). Price was extremely important to participants. All participants were aware that LFM costs more than traditional milk, and this was viewed negatively. Although participants were aware of several LFM brands, they most often chose to purchase store brands instead of name or national brands, citing price as the main driver of choice. Although the price of LFM was important to participants, all participants stated that dairy milk that does not cause stomach discomfort was worth paying a higher price for.

Participants preferred half-gallon cardboard cartons to other packaging and sizing. There was limited interest in package sizes that were bigger or smaller than a half-gallon, even if the entire household drank LFM. Fat content, protein content, and the expiration date were cited as the most important information that could be found on the package, as well as "Lactosefree" prominently displayed on the label. Participants preferred packages where this information was easy to find. The color of the package was also important to participants. A colorful package, or one that used color to distinguish between fat content, was more important to participants than being able to see the milk inside the package. Label claims on packages such as "high protein," "organic," and "high calcium" were appealing to participants, but generally only affected purchases if comparing $2 \mathrm{LFMs}$ of the same price.

Most participants were unfamiliar with LFM processing. After being presented with information regarding lactose removal methods (lactase enzyme and ultrafiltration), participants did not have a preference, but stated their desire for whichever process resulted in the lowest final price, regardless of socio-economic status. Most participants were aware that pasteurization was a heat treatment applied for safety and shelf life but did not understand the differences between pasteurization and ultrapasteurization, or that ultrapasteurization resulted in a longer product shelf life. Before being presented with information, participants did not like the word "ultrapasteurization," stating that it sounded "expensive" and "scientific." After reading an information handout provided on pasteurization versus ultrapasteurization, their opinions changed. The longer shelf life resulting from ultrapasteurization was seen as a good trade-off for the higher price of LFM; however, they still did not like the word "ultrapasteurization."

Next, participants were asked about the sensory characteristics of LFM compared with traditional milk, as well as some other perceptions of the product. All consumers thought that the biggest difference between
LFM and traditional milk was the increased sweetness of LFM. Some participants also thought LFM had a lower viscosity than traditional milk. Sweetness was cited as one of the most distinguishing characteristics between different brands of LFM, along with flavor in general. When asked how participants would want LFM to taste, almost all responded that they would want it to taste exactly the same as traditional milk; however, when asked how the sensory properties of LFM could be improved, only a small minority indicated that the sweetness of LFM should be reduced to better resemble that of traditional milk. Most participants did not view LFM as a "natural" product; however, the benefits from access to dairy milk they could consume without discomfort was more important than its perception as natural. Finally, participants were asked about applications for LFM. All used LFM as a beverage, and about half also used it for cooking. Those who did not use LFM for cooking were skeptical about using it in recipes, indicating that they were not sure how the increased sweetness of LFM would affect the dish. However, those who used LFM for cooking found it to be interchangeable with traditional milk in all recipes.

\section{Adaptive Choice-Based Conjoint Survey}

Utility scores from hierarchical Bayesian analysis are reported as zero-centered values. More positive scores indicate more appealing levels within each attribute (Orme, 2010). The utility scores from the overall population $(\mathrm{n}=331)$ indicated that the ideal LFM product was low in price ( $\$ 2.00-\$ 4.00$ per half-gallon), packaged in a half-gallon cardboard carton, ultrapasteurized, and had the same sweetness and texture as traditional milk (Figure 2), consistent with focus group results. For the overall population, price was the most important attribute by a significant margin $(P<0.05$; Figure 3$)$. Most of the results obtained from the ACBC survey reflected the findings of the focus groups, price being the most notable example. In a focus group setting with LFM consumers, many conversations led to the topic of price and its importance to participants. Survey results from LFM consumers indicated the same conclusion: price was extremely important to LFM consumers and heavily influenced purchase decisions.

As seen in Figure 2, cardboard half-gallon packages were the most preferred for LFM consumers, which was also supported by focus group discussions. Additionally, sweetness and texture that resembled that of traditional milk were most appealing $(P<0.05)$. In focus groups, LFM consumers liked longer shelf life. Ultrapasteurized was defined in the ACBC via shelf life. In contrast to traditional milk consumers, LFM consumers preferred ultrapasteurization over conventional pasteurization $(P$ 


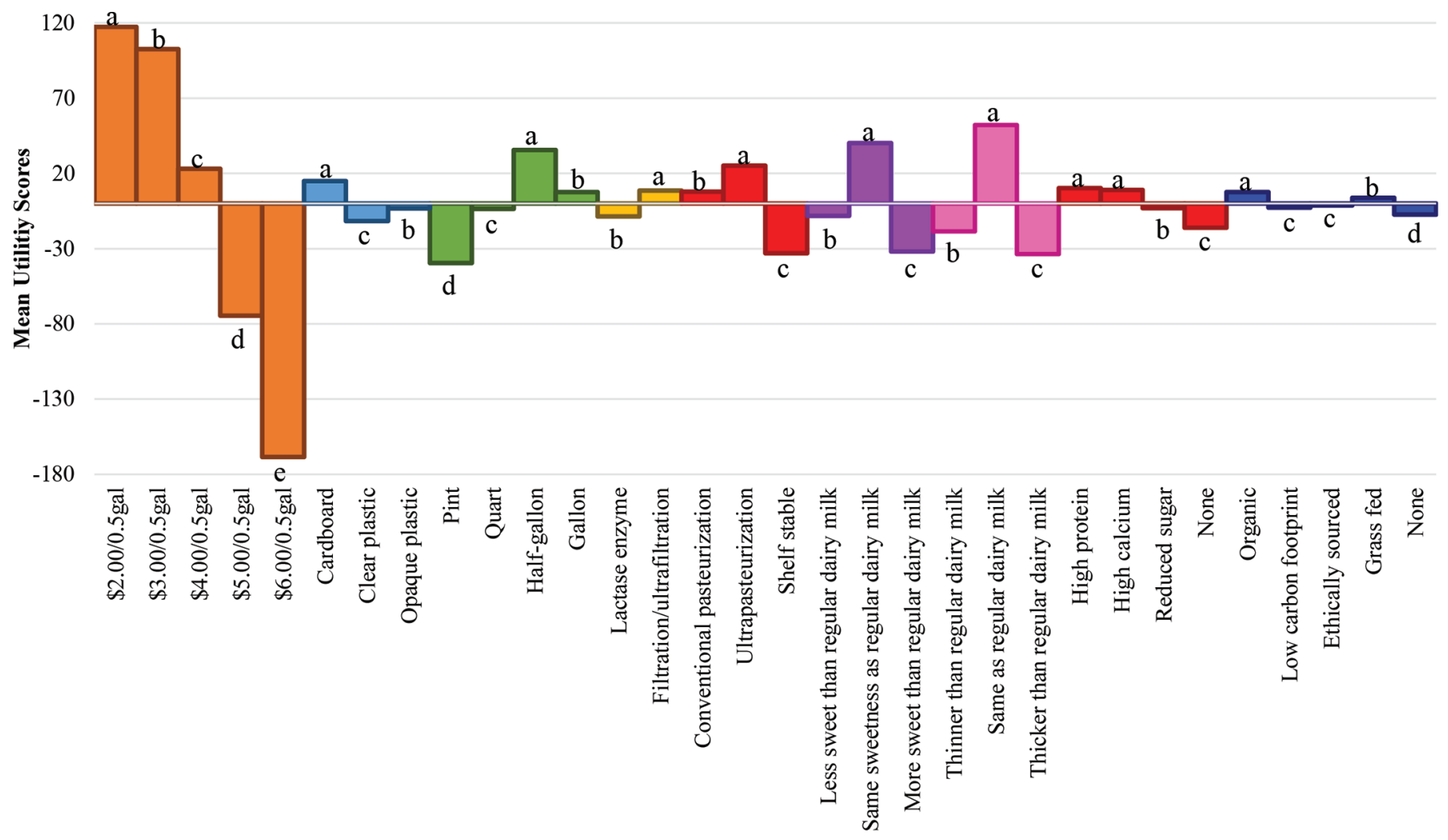

Attribute Level

Figure 2. Mean adaptive choice-based conjoint (ACBC) utility scores for the overall population $(\mathrm{n}=331)$ for lactose-free milk attributes. Different letters $(\mathrm{a}-\mathrm{d})$ over levels within the same attribute indicate significant differences $(P<0.05)$.

$<0.05$ ) (Harwood and Drake, 2018). These data suggest that the longer shelf life of LFM has value and is appealing to these consumers. Based on the importance scores of each attribute, shelf life was one of the most important LFM attributes after price. This, along with the fact that ultrapasteurization was the most appealing pasteurization method, suggests that LFM consumers have come to expect LFM to be ultrapasteurized, given that all commercial LFM products are currently ultrapasteurized to our knowledge. However, it is clear that LFM consumers, like traditional milk consumers, do not prefer shelf-stable milk. Although they view the extended shelf life of ultrapasteurization as a major benefit, LFM consumers expect milk to require refrigeration. Nutrition claims and label claims did not appear to be of importance to the overall population of LFM consumers when making purchase decisions compared with many of the other attributes $(P<0.05)$.

Raw utility scores from the ACBC survey were segmented into 3 distinct consumer clusters based on participant responses and were named according to their results: the bargain cluster $(\mathrm{n}=152)$, the performance cluster $(\mathrm{n}=103)$, and the pragmatic cluster $(\mathrm{n}=76)$.
These clusters were mostly distinguished by their price importance scores. The bargain cluster was defined by its high price importance score, the highest of all consumer clusters $(P<0.05)$. By putting a vast quantity of importance on price, this consumer segment was not greatly affected by other LFM attributes when making purchase decisions. While the bargain cluster did not constitute most of the survey participants, it was the largest consumer cluster, indicating a significant portion of LFM consumers were extremely price sensitive. The performance cluster had the lowest importance score for the price attribute compared with the other 2 clusters, and had the highest importance scores for all other attributes with package size as the only exception $(P<0.05)$. These results indicate that consumers in this segment were not as price sensitive as other consumer clusters, and tended to put more weight on product performance when making purchase decisions.

The pragmatic cluster exhibited aspects of both the bargain and performance clusters, with a price importance score in between that of other clusters $(P<$ $0.05)$, in addition to many other attributes. However, the pragmatic cluster had the highest importance score 
for package size compared with the other clusters $(P<$ $0.05)$, and it was the second most important attribute of this consumer segment, following price. The pragmatic cluster also had a high importance score for package material, along with the performance cluster, which scored at parity $(P>0.05)$. These results indicate that a significant portion of the population heavily considers packaging attributes when making purchase decisions.

\section{Maximum Difference Scaling}

The results of the MaxDiff exercise closely resembled results from the ACBC survey and focus group discussions (Table 2). The most important LFM component to both the overall population and each individual consumer cluster was "the fact that the milk is lactosefree" $(P<0.05)$. This is logical and supports the findings of the focus groups: the majority of consumers begin purchasing LFM because they or someone in their household is lactose intolerant. The first deviation in the MaxDiff results from the ACBC results was that "flavor of the milk" was the second most important LFM component, even above price $(P<0.05)$, whereas price was the most important attribute found in the ACBC survey, and sweetness the third most important. One possible explanation for this difference was how this attribute was represented. In the ACBC survey, it was presented as "sweetness," as opposed to "flavor of the milk" in the MaxDiff exercise. This might indicate that LFM consumers interpret "flavor" differently from "sweetness" and see the flavor of LFM as more than its sweet taste. The next most important LFM components for the overall population were "price" and "fat content," which scaled at parity $(P>0.05)$. These results were also expected. Price is almost always one of the most important attributes for food products. Fat content was not included in the ACBC survey, but was expected to be very important to LFM consumers. Most milk consumers are very strict about the milk fat content they purchase, and do not deviate from their selected fat percentage (McCarthy et al., 2017a). The importance of fat content was also noted by focus group discussions with LFM consumers in this study. Another difference between the MaxDiff results and the ACBC results was that "package size" was among the least important LFM components in the MaxDiff exercise, but one of the most important in the ACBC exercise. An explanation for this could be that the MaxDiff exercise preceded the ACBC exercise in the survey, so the participants had not yet been exposed to all possible package sizes presented in the ACBC exercise (pint, quart, half-gallon, and gallon), and only drew from their prior purchase experiences with LFM when participating in the MaxDiff exercise. The vast

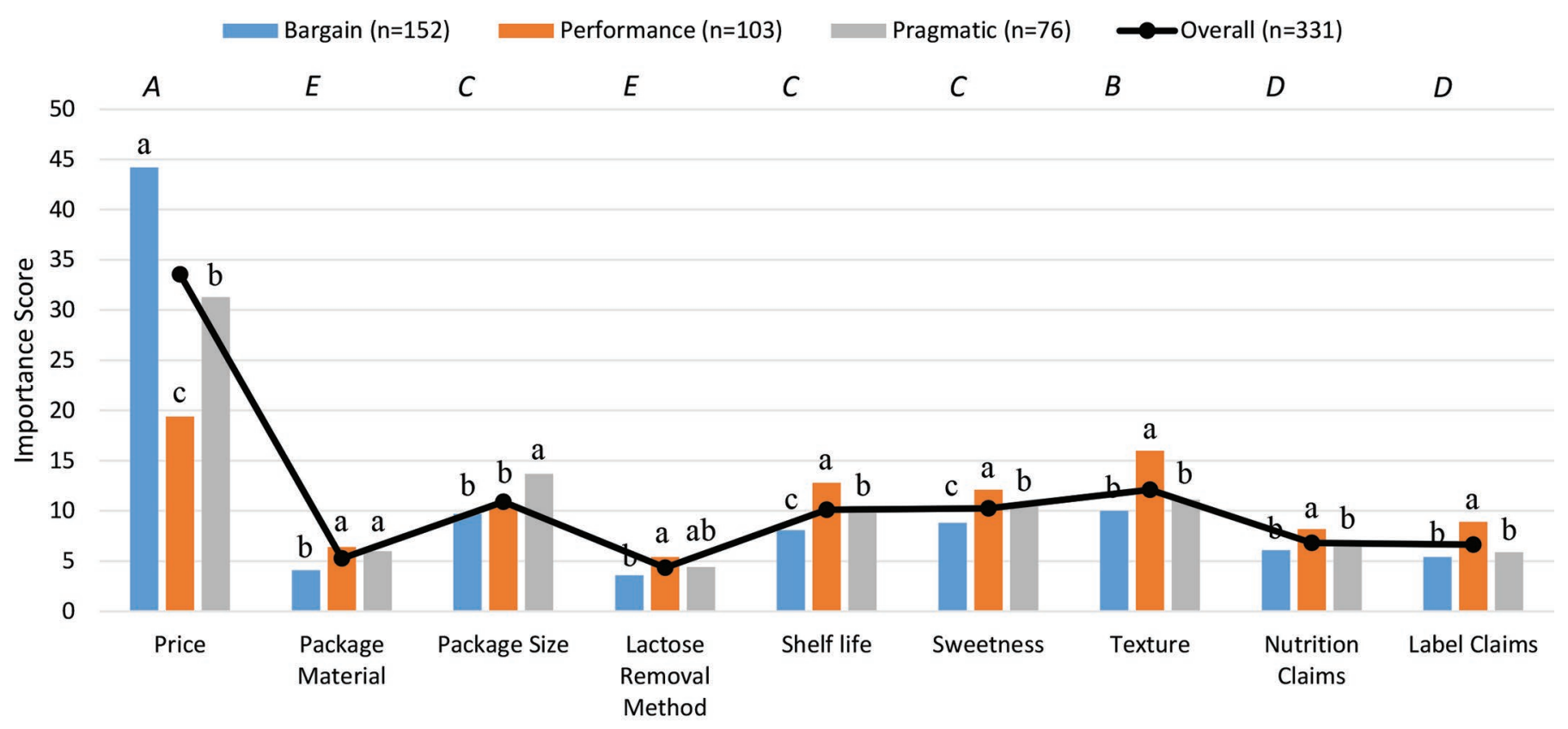

LFM Product Attribute

Figure 3. Importance scores for lactose-free milk (LFM) attributes from the adaptive choice-based conjoint survey for consumer clusters and

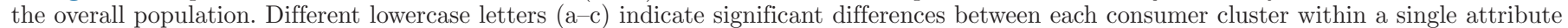

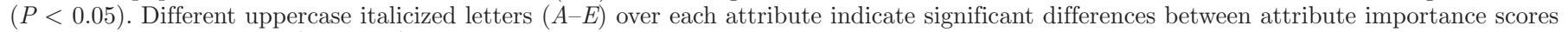
for the overall population $(P<0.05)$. 
majority of LFM is packaged in half-gallon packages, so it is possible LFM consumers had not considered other packaging options before participating in the ACBC survey.

Similar to the ACBC survey, the importance of price was a distinguishing factor among the 3 consumer clusters in the MaxDiff exercise, with price being the most important to the bargain cluster $(P<0.05)$. Many of the other results from the MaxDiff cluster analysis were similar to the ACBC cluster analysis. In the MaxDiff, the performance cluster had a higher score $(P<0.05)$ for "organic" than the other 2 clusters, which mirrors the results of the ACBC, and demonstrates the importance of other product attributes that consumers in the performance cluster consider when making purchase decisions. The performance cluster had the highest score $(P<0.05)$ for "brand," which was expected given the value-added mindset that this cluster demonstrated.

\section{Kano Model}

The results of the Kano model indicate the overall population of LFM consumers were indifferent toward the majority of LFM attributes (Table 3). It is important to consider that the Kano Model classifies attributes into a rigid category and does not consider the total distribution of each classification's scores, meaning the indifferent classification had the highest score, but was not the only classification selected. Price was expected to be classified as one-dimensional considering consumer satisfaction tends to decrease linearly as price increases. Utility scores in the price attribute from the ACBC decreased as price increased (Figure 2 ). This trend was also observed when discussing price with LFM consumers during the focus groups. However, "milk that is lactose-free" was not expected to be classified as one-dimensional, but was expected to be classified as must-have. Although the one-dimensional classification had the highest score for this attribute, it is important to note that less than $10 \%$ of the overall population separated it from being classified as musthave. This stipulates that there is a significant portion of LFM consumers that consider lactose-hydrolysis as a must-have for product satisfaction. One possible explanation for why the majority of survey participants classified this attribute as one-dimensional is based on results from the focus groups. Only about half the LFM consumers that participated in the focus groups exclusively purchased LFM. The others indicated that they purchased traditional milk for other members of their family or for cooking applications. It is possible that in this context, milk does not have to be lactose-free in order for LFM consumers to derive satisfaction, leading to a one-dimensional classification for the attribute. We also learned from focus group discussions that there are varying degrees of lactose sensitivity among individuals, or at least the perception of variable sensitivity. With this in mind, it is possible that some less-sensitive LFM consumers do not require that all the lactose be removed, but will derive more satisfaction as the lactose content decreases, leading to a one-dimensional classification.

Table 2. Maximum difference (MaxDiff) scores $^{1}$ for lactose-free milk (LFM) for consumer clusters and overall population

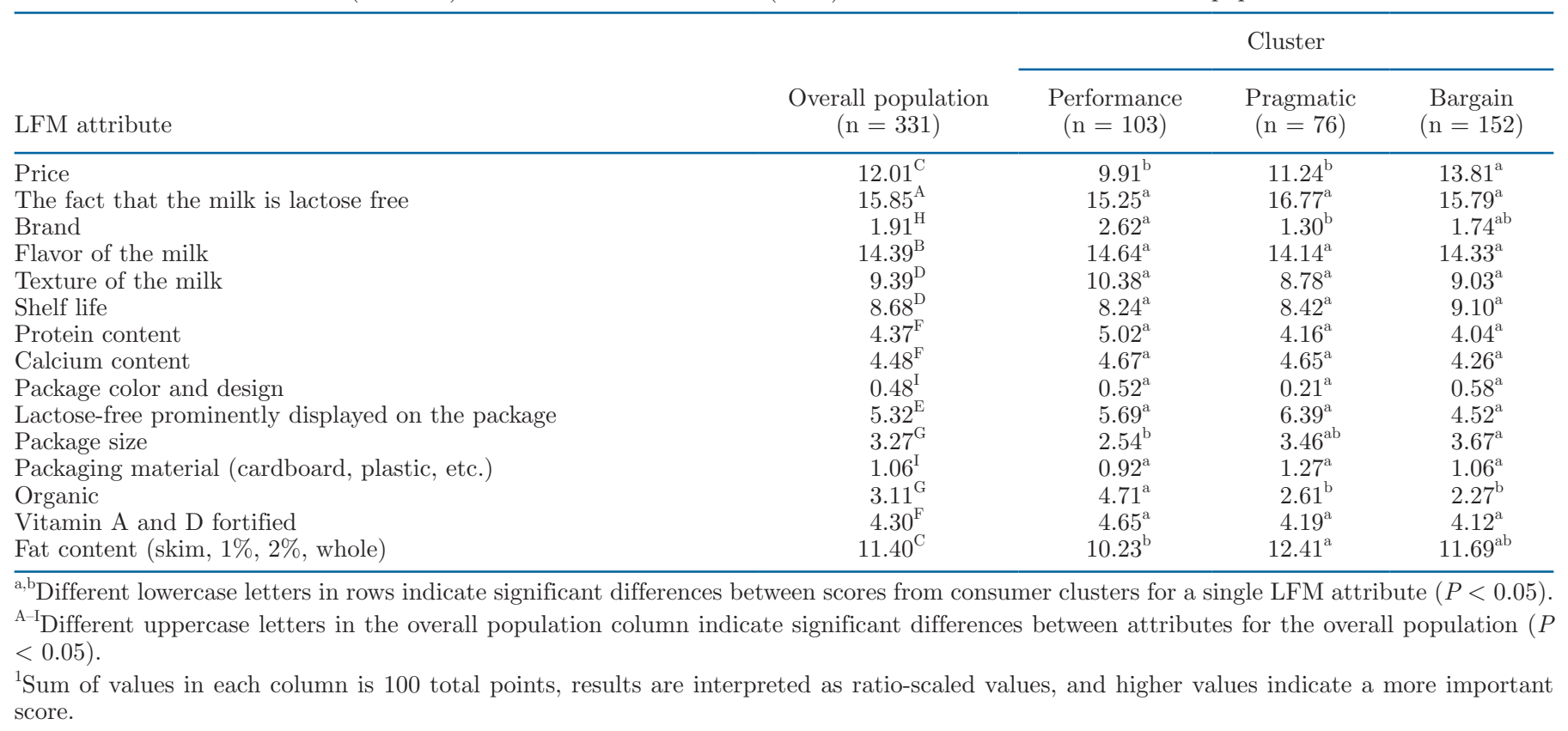


Similar to the MaxDiff exercise results, the results from the Kano model were segmented using the same consumer clusters derived from the ACBC survey. Each cluster mostly resembled the results of the overall population, with some notable differences. The only difference between the results of the bargain cluster and that of the overall population is the attribute "milk that is lactose-free" was classified as a must-have. This is an important distinction; given that the bargain cluster is the largest consumer cluster of the 3 , it demonstrates the importance of lactose-hydrolysis on consumer satisfaction of LFM. A distinction between the performance cluster and the overall population was the attribute "milk that is low in price ( $\$ 2.00-\$ 4.00$ per half-gallon)" was classified as indifferent. This was expected from the performance cluster and reaffirms the results of the ACBC survey. Another difference between the performance cluster and the overall population was that the attribute "milk that has the same viscosity/mouthfeel as regular milk" was classified as one-dimensional, rather than indifferent. These results indicate that as the texture of LFM deviates from that of traditional milk, consumer satisfaction decreases. Since the performance cluster was more concerned with sensory attributes of LFM than other clusters, this classification was anticipated and supports the results of the ACBC survey.
This attribute was also classified as one-dimensional by the pragmatic cluster, further explaining results from the ACBC survey that texture is an important attribute for LFM. The final distinction between the pragmatic cluster and the overall population was the attribute "lactose-free milk that has the same sweetness as regular milk" was classified as attractive rather than indifferent. These results signify that consumers of the pragmatic cluster do not expect LFM to have the same sweetness as traditional milk but will be pleased if it does. This falls in line with what is believed about the pragmatic cluster: they will appreciate certain product attributes, but will not let these attributes heavily affect purchase decisions as much as price.

\section{Descriptive Analysis}

Sensory differences were documented among the 9 commercial 2\% LFMs evaluated (Table 4). The milks differed in all attributes except for milkfat flavor (Figure 4). Four of the milks had distinct paperboard flavor. It is important to note that all milks were packaged in a paperboard carton, except for LFM2. Only 2 milks, LFM2 and LFM4, exhibited eggy flavor. These results were somewhat unexpected considering that ultrapasteurized milk tends to have distinct intensities of eggy

Table 3 . Kano classifications ${ }^{1}$ for consumer clusters and the overall population for lactose-free milk

\begin{tabular}{|c|c|c|c|c|}
\hline \multirow[b]{2}{*}{ Item } & \multicolumn{3}{|c|}{ Cluster } & \multirow{2}{*}{$\begin{array}{c}\text { Overall } \\
\text { population } \\
(\mathrm{n}=331)\end{array}$} \\
\hline & $\begin{array}{l}\text { Bargain } \\
(\mathrm{n}=152)\end{array}$ & $\begin{array}{l}\text { Performance } \\
\qquad(\mathrm{n}=103)\end{array}$ & $\begin{array}{l}\text { Pragmatic } \\
(\mathrm{n}=76)\end{array}$ & \\
\hline Milk that is low in price $(\$ 2.00-\$ 4.00$ per half-gallon $)$ & $\mathrm{D}$ & $\mathrm{I}$ & $\mathrm{D}$ & $\mathrm{D}$ \\
\hline Milk that is lactose free & $\mathrm{M}$ & $\mathrm{D}$ & $\mathrm{D}$ & $\mathrm{D}$ \\
\hline Milk that is a store brand & I & I & $\mathrm{I}$ & I \\
\hline Milk that is a name/national brand & $\mathrm{I}$ & $\mathrm{I}$ & $\mathrm{I}$ & I \\
\hline Milk that has a long expiration date ( $>50 \mathrm{~d}$, unopened in refrigerator) & $\mathrm{I}$ & $\mathrm{I}$ & $\mathrm{I}$ & I \\
\hline Milk that has a high protein content & $\mathrm{I}$ & $\mathrm{I}$ & $\mathrm{I}$ & $\mathrm{I}$ \\
\hline Milk that has a high calcium content & I & $\mathrm{I}$ & $\mathrm{I}$ & $\mathrm{I}$ \\
\hline Milk that has an attractive package & $\mathrm{I}$ & $\mathrm{I}$ & $\mathrm{I}$ & $\mathrm{I}$ \\
\hline Milk that comes in a half-gallon package & I & I & $\mathrm{I}$ & $\mathrm{I}$ \\
\hline Milk that comes in a gallon package & $\mathrm{I}$ & $\mathrm{I}$ & $\mathrm{I}$ & $\mathrm{I}$ \\
\hline Milk that comes in a cardboard carton & $\mathrm{I}$ & $\mathrm{I}$ & $\mathrm{I}$ & $\mathrm{I}$ \\
\hline Milk that comes in a clear plastic jug & $\mathrm{I}$ & $\mathrm{I}$ & $\mathrm{I}$ & $\mathrm{I}$ \\
\hline Milk that comes in an opaque plastic jug & $\mathrm{I}$ & $\mathrm{I}$ & $\mathrm{I}$ & $\mathrm{I}$ \\
\hline Milk that is organic & $\mathrm{I}$ & $\mathrm{I}$ & $\mathrm{I}$ & $\mathrm{I}$ \\
\hline Milk that is vitamin fortified & $\mathrm{I}$ & $\mathrm{I}$ & $\mathrm{I}$ & $\mathrm{I}$ \\
\hline Milk that is the fat content I usually buy & $\mathrm{I}$ & $\mathrm{I}$ & $\mathrm{I}$ & $\mathrm{I}$ \\
\hline Lactose-free milk that uses filtration to remove lactose & $\mathrm{I}$ & $\mathrm{I}$ & $\mathrm{I}$ & $\mathrm{I}$ \\
\hline Lactose-free milk that uses enzymes to remove lactose & $\mathrm{I}$ & $\mathrm{I}$ & $\mathrm{I}$ & $\mathrm{I}$ \\
\hline Lactose-free milk that has the same sweetness as regular milk & $\mathrm{I}$ & $\mathrm{I}$ & A & $\mathrm{I}$ \\
\hline Milk that has a reduced sugar content & $\mathrm{I}$ & $\mathrm{I}$ & $\mathrm{I}$ & $\mathrm{I}$ \\
\hline Milk that has as low carbon footprint & $\mathrm{I}$ & $\mathrm{I}$ & $\mathrm{I}$ & $\mathrm{I}$ \\
\hline Milk that is ethically sourced & $\mathrm{I}$ & $\mathrm{I}$ & $\mathrm{I}$ & $\mathrm{I}$ \\
\hline Milk that comes from grass-fed cows & $\mathrm{I}$ & $\mathrm{I}$ & $\mathrm{I}$ & $\mathrm{I}$ \\
\hline Milk that has the same viscosity/mouthfeel as regular milk & $\mathrm{I}$ & $\mathrm{D}$ & $\mathrm{D}$ & $\mathrm{I}$ \\
\hline
\end{tabular}

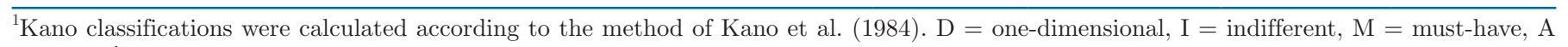
$=$ attractive. 


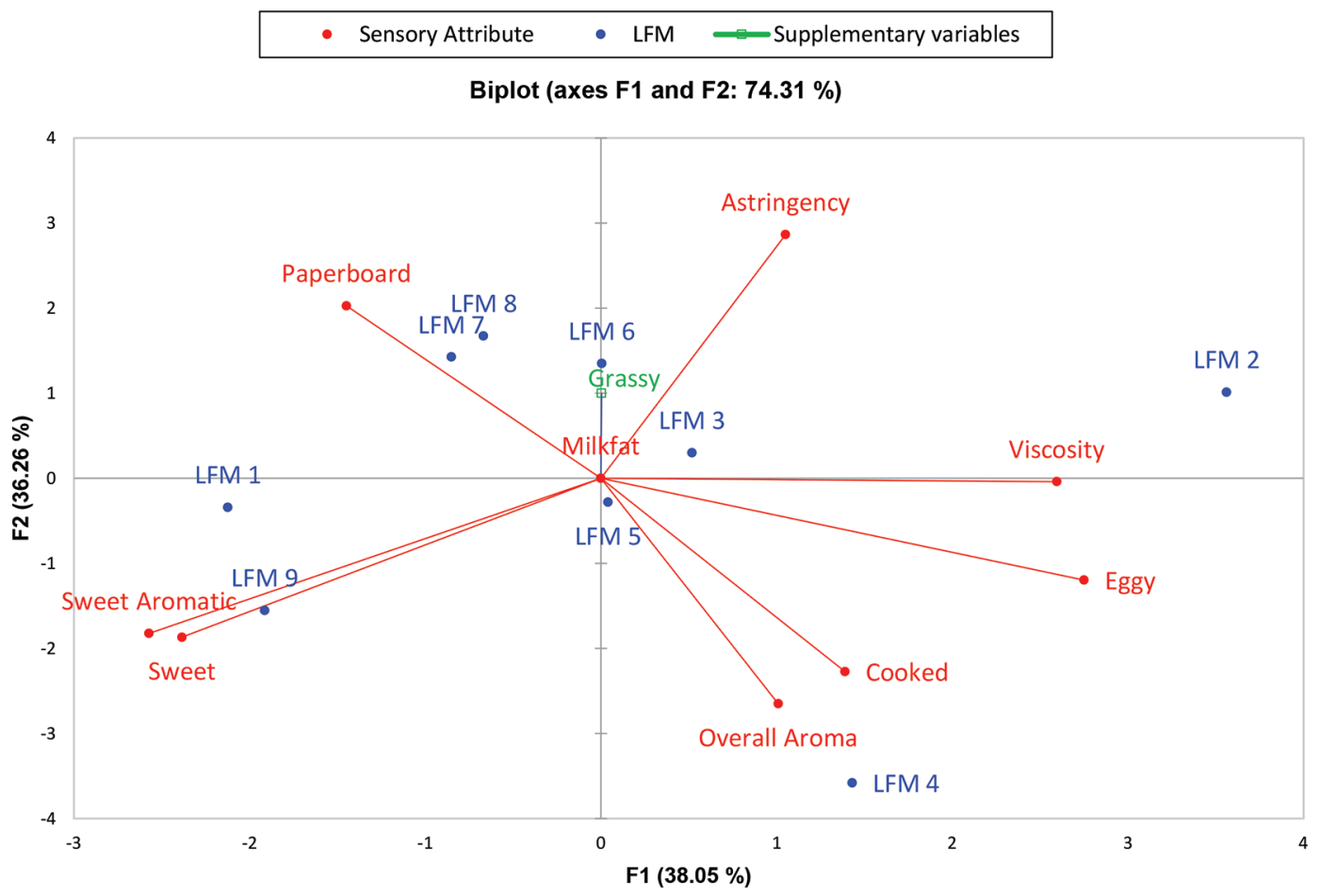

Figure 4. Principal component analysis biplot of descriptive analysis data for 9 lactose-free milks (LFM).

flavor due to the increased heat treatment. A recent study also shows that the volatile sulfur compounds that create eggy flavor in milk result from Maillard reactions between reducing sugars (lactose) and cysteine and methionine amino acids (Jo et al., 2018). Considering lactose is hydrolyzed into glucose and galactose, which are both reducing sugars, an increase in eggy flavor might be expected in LFM compared with traditional milk. The only sample that exhibited grassy flavor was LFM6, and this milk was an organic grass fed LFM, so grassy flavor was expected. The milks eval- uated were different in viscosity $(P<0.05)$. The most viscous milks were LFM2 and LFM6 , and LFM1 and LFM7 were the least viscous. The most distinguishing attribute between milks was sweet taste intensity, which was responsible for the most variation among milks. The median sweet taste intensity among LFMs evaluated was 3.2 , but sweet taste intensities ranged from 1.5 (LFM2) to 4.2 (LFM9). This large variation in sweet taste intensity among the 9 LFMs evaluated is likely due to the starting concentration of lactose in each milk. An important distinction for LFM2 is that

Table 4. Descriptive analysis trained panel means ${ }^{1}$ of 9 samples of lactose-free milk (LFM)

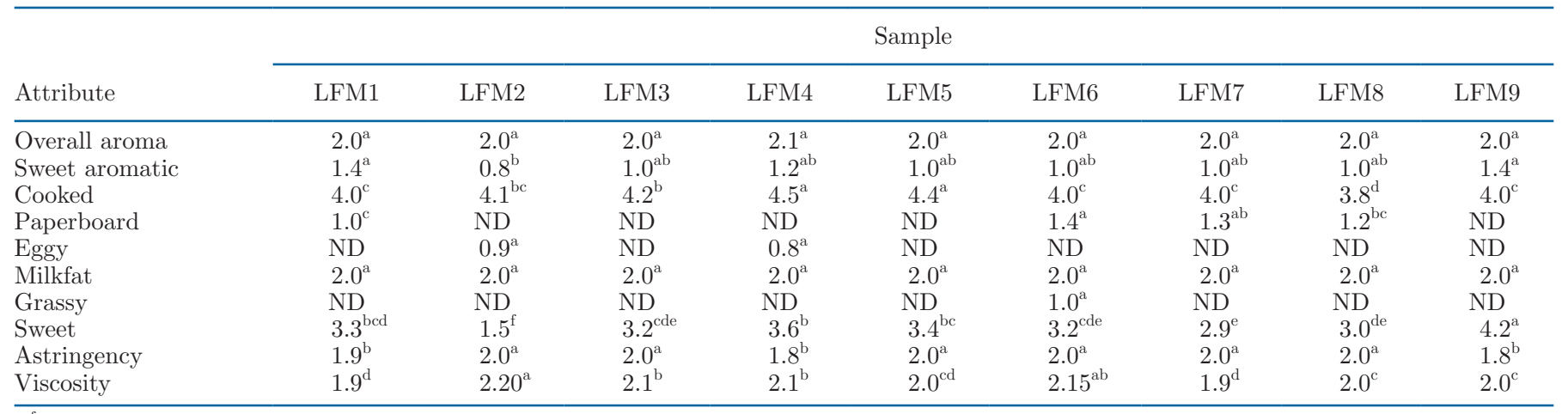

${ }^{\mathrm{a}-\mathrm{f}}$ Different letters in rows indicate significant differences $(P<0.05)$.

${ }^{1}$ Attributes were scored on a 0 - to 15 -point scale, with $0=$ not intense at all and $15=$ extremely intense. ND $=$ not detected. 
it used a combination of lactase enzyme and ultrafiltration to remove lactose, whereas other milks solely used the lactase enzyme. Ultrafiltration would have greatly reduced the starting lactose concentration in this sample, resulting in a largely reduced sweet taste, and likely increased viscosity, cooked flavor intensity, and eggy flavor intensity due to the increase in protein concentration.

\section{Consumer Acceptance Taste Test}

The same 9 LFMs evaluated by the trained sensory panel were evaluated by LFM consumers $(\mathrm{n}=160)$ (Table 5). Flavor and sweetness were the most important sensory attributes to LFM consumers, which we concluded because the milks that received the lowest overall liking scores (LFM2 and LFM8) also received the lowest scores for flavor liking and sweetness liking $(P<0.05)$. Milks that received low overall liking scores also received the lowest quality and purchase intent scores.

Overall liking scores from the consumer acceptance test were used to segment consumers into distinct clusters based on which milks they most preferred, and each cluster was named accordingly: the sweetness cluster $(\mathrm{n}=86)$, the cooked flavor cluster $(\mathrm{n}=42)$, and the balanced cluster $(\mathrm{n}=32)$ (Figure 5). Similar to the ACBC survey, 3 distinct clusters were identified for the consumer acceptance test population. This was an interesting discovery because the consumers that participated in the ACBC survey and the consumer acceptance test were not necessarily the same, but with the potential for some crossover. These results might indicate that there are truly 3 distinct types of LFM

Table 5. Consumer acceptance liking means for 9 samples of lactose-free milks (LFM; $\mathrm{n}=160$ )

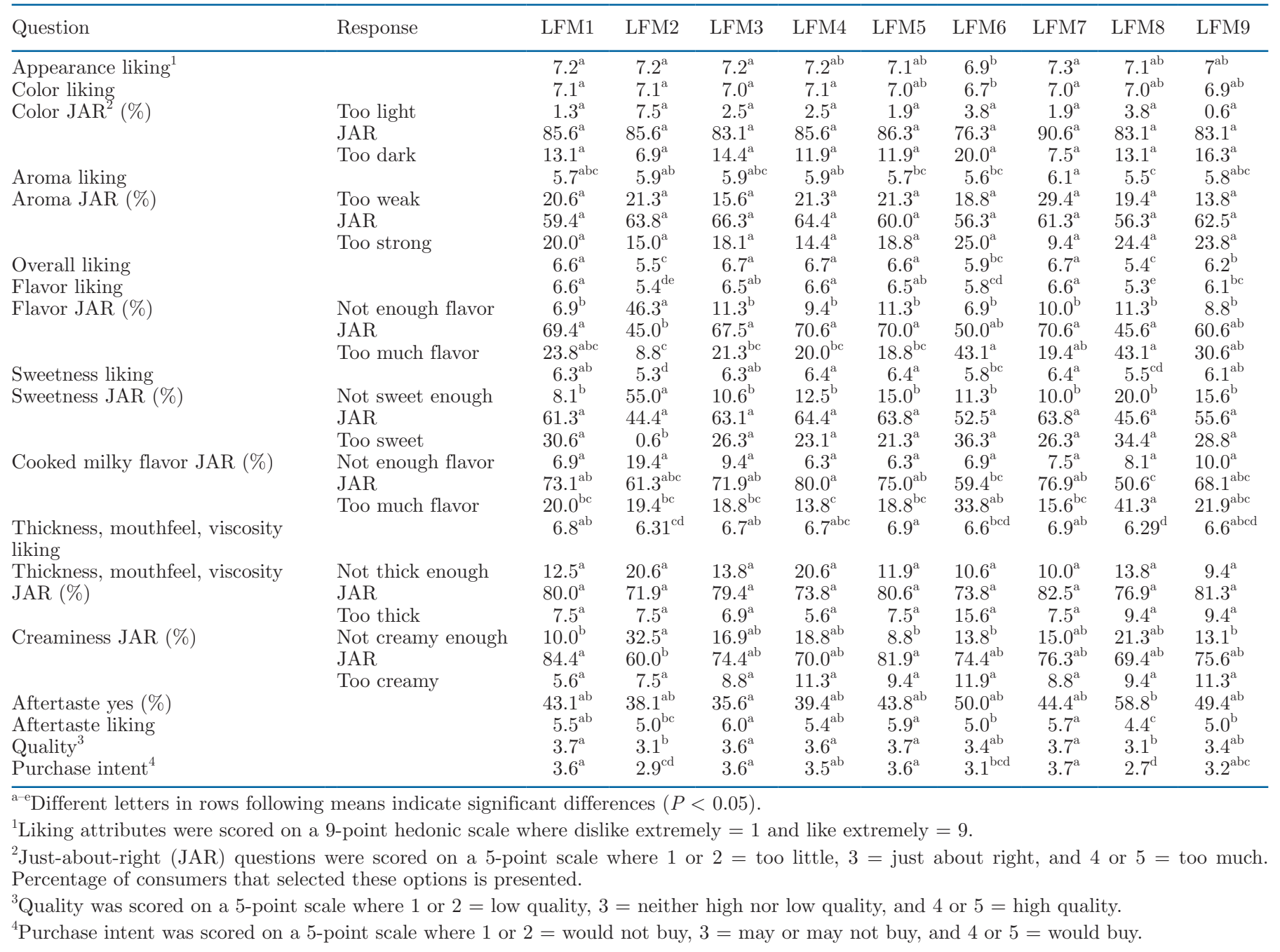


consumers. Based on the consumer segmentation results, the overall liking score for LFM2 was the major factor for determining consumer segmentation.

A high overall liking score for LFM2 was the most distinguishing characteristic of the cooked flavor cluster. Although LFM2 received the lowest overall liking score for the overall population $(P<0.05)$, the consumers from the cooked flavor cluster gave LFM2 a score of 7.1 in overall liking, their most preferred sample. Conversely, the balanced cluster was mainly characterized by an extremely low overall liking score for LFM2 (2.7). Finally, the sweetness cluster had the highest overall liking score for all LFMs except for LFM2. These results possibly indicate that these consumers either were not able to distinguish samples from one another unless there was a large difference in sweetness (as was the case with LFM2), or they are much more easily pleased than consumers from other clusters. It is important to consider that the sweetness cluster was the largest consumer cluster and constituted most of the consumers that participated in the consumer acceptance test. This might indicate that many more consumers are much more easily pleased by various LFM products, based purely on sensory perception, than would have been anticipated from the focus group and online survey results. For example, the MaxDiff exercise found flavor to be one of the most important LFM attributes that could affect purchase decisions, yet the majority of consumers (the sweetness cluster) were generally pleased by all LFM evaluated. Even LFM2, which received the lowest overall liking score from the sweetness cluster, was still "liked" with an overall liking score of 5.8.

The external preference map from partial least squares regression (Figure 6) helps to further understand distinctions between consumer clusters, based on overall liking scores. As seen in Figure 5, the cooked flavor cluster is largely associated with a high overall liking score for LFM2. Figure 6 illustrates that through their relationship with LFM2, the cooked flavor cluster can also be characterized by preference for LFM that are high in viscosity, eggy flavor intensity, and cooked flavor intensity. One of the most important discoveries learned from Figure 6 is the market potential for LFM products similar to LFM2 among consumers. Lactosefree milk 2 was an ultrafiltered, high protein, low sugar LFM. Although LFM2 received the lowest overall liking score for the overall population $(P<0.05)$, it is clear that there is market potential for this product in the cooked flavor cluster consumers. Additionally, Figure 6 demonstrates sweetness was a driver of disliking for the

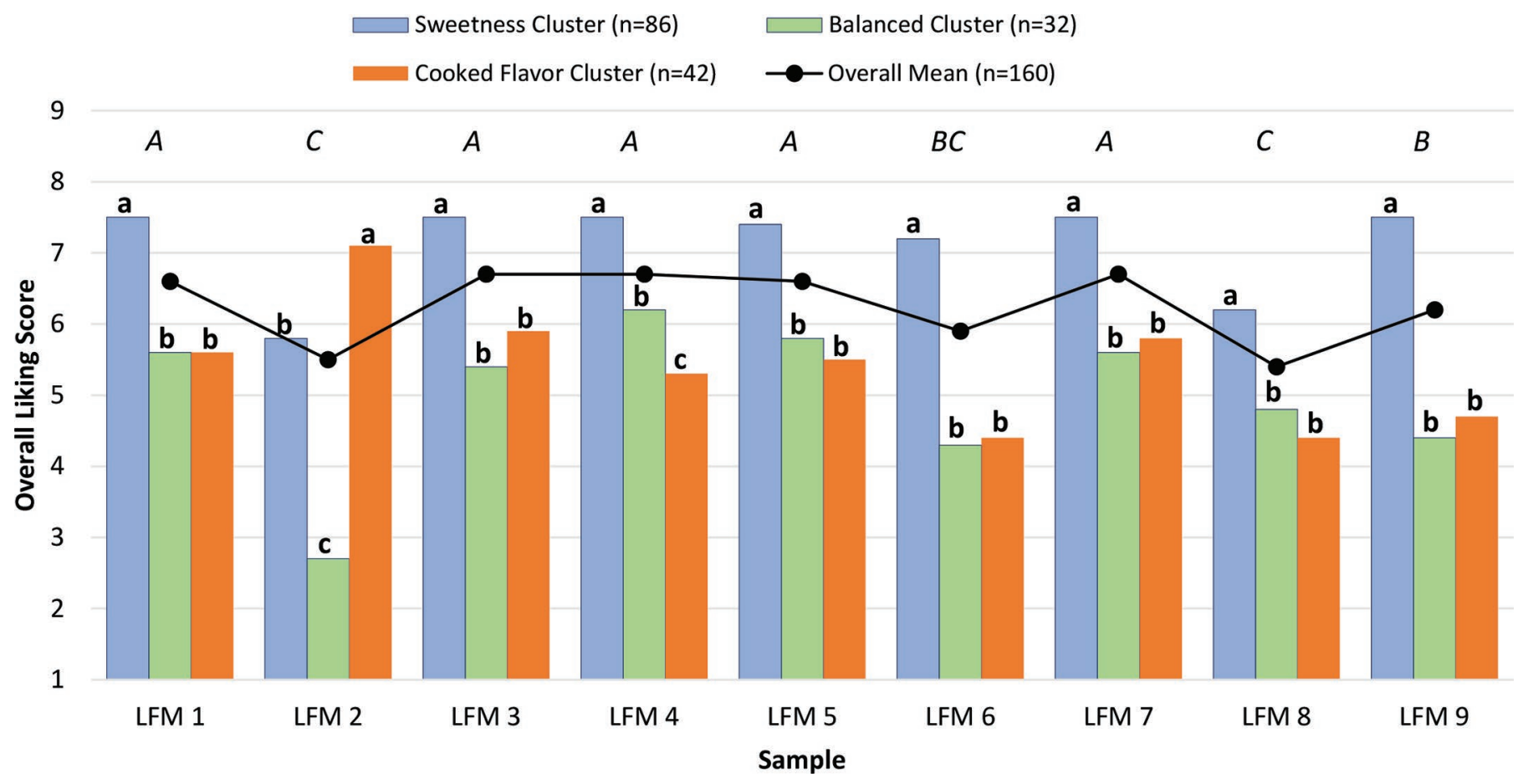

Figure 5. Mean overall liking scores for 9 lactose-free milks (LFM) for the overall population $(\mathrm{n}=160)$ and by consumer cluster. Different lowercase letters $(\mathrm{a}-\mathrm{c})$ within each LFM sample indicate significant differences between each consumer cluster $(P<0.05)$. Different uppercase italicized letters $(A-C)$ over each LFM sample indicate significant differences for overall liking score for the overall population $(P<0.05)$. Overall liking was scored on a 9-point hedonic scale where dislike extremely $=1$ and like extremely $=9$. 


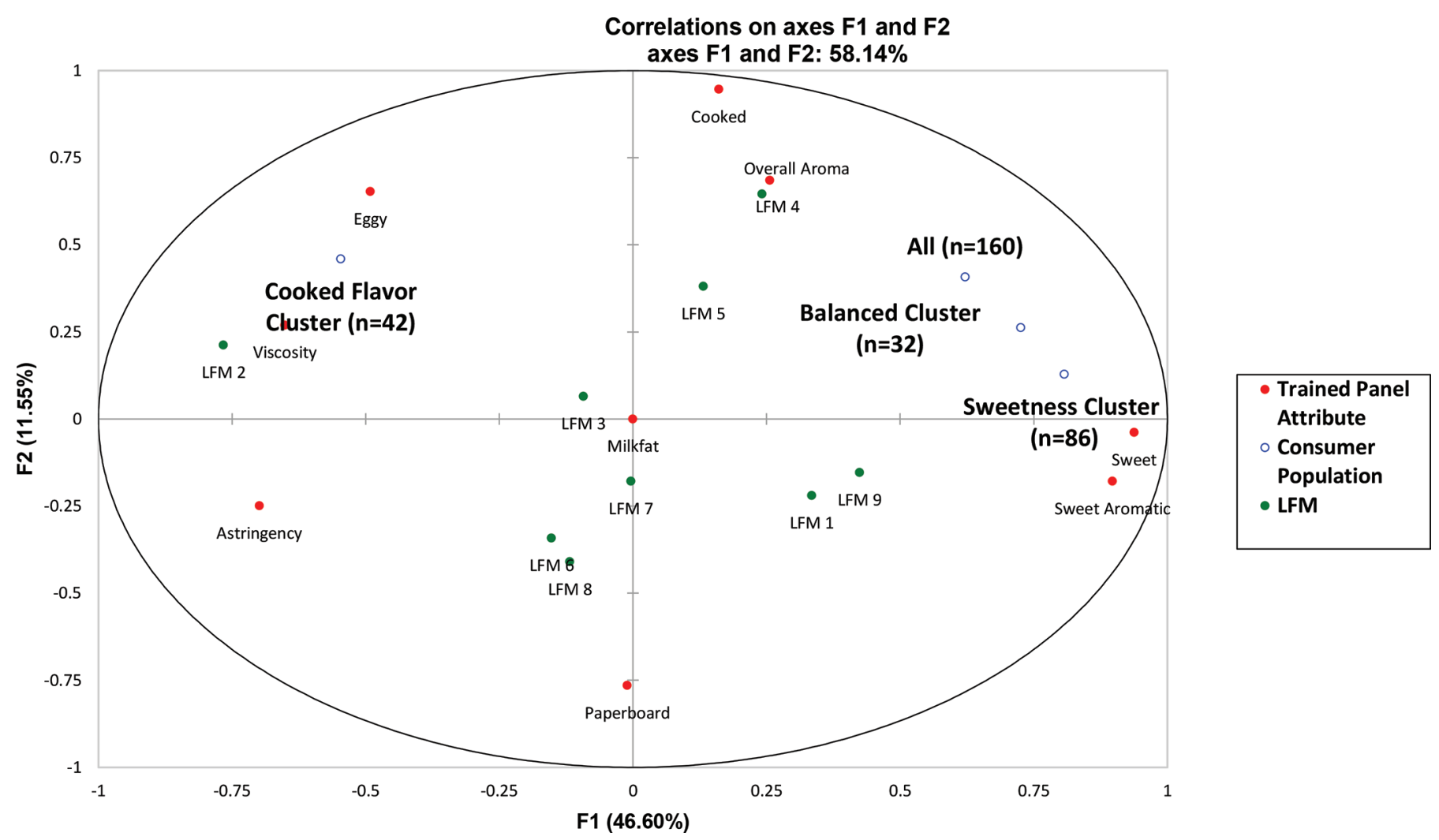

Figure 6. Partial least squares regression biplot of consumer overall liking clusters and descriptive analysis results for lactose-free milk (LFM).

cooked flavor cluster, but it was a driver of liking for the sweetness and balanced clusters. The balanced cluster could also be characterized by its drivers of disliking: high viscosity, eggy flavor, and cooked flavor. This can be seen most clearly in Figure 5. The balanced cluster scored LFM2 at 2.7 in overall liking, which was the only milk that possessed these drivers of disliking and lacked sweetness, a driver of liking. Although, sweetness was a driver of liking for the sweetness cluster, this cluster did not appear to a have a specific driver of disliking, especially when considering its overall liking score of LFM2 (Figure 5). The sweetness cluster gave LFM2 a score of 5.8, which was the lowest score given by the sweetness cluster, but still indicated slight liking. The lack of sweetness was likely most responsible for the reduced overall liking score.

An important discovery learned from the consumers acceptance test was the importance of sweet taste to the overall population of LFM consumers as a driver of liking. A good example of this can be seen when comparing LFM2 and LFM4. As seen in Figure 4 and Table 4, LFM2 and LFM4 had a very similar overall sensory profile. The major difference between the 2 milks was their sweet taste intensity. When consider- ing consumer acceptance test results, LFM2 received the lowest overall liking score, while LFM4 received the highest score. Considering these milks were very similar in all other sensory attributes except for sweet taste intensity, the results demonstrated the importance of sweetness to the average LFM consumer. This was an important discovery, especially when considering the findings of the focus groups and online survey, where consumers overwhelmingly stated that they would most prefer LFM that has the same sweetness as traditional milk.

Many of the results of this study reflected those of previous studies on fluid milk. Most notably, Harwood and Drake (2018) noted that price was the most important attribute of traditional fluid milk to consumers making purchase decisions. This principle appears to be even more extreme for LFM consumers, likely due to the higher price point of LFM when compared with traditional fluid milk. Fat content played a large role in purchase decisions for LFM, also confirmed in previous studies with milk (McCarthy et al., 2017b; Harwood and Drake, 2018). Harwood and Drake (2018) also found that flavor of the milk was very important to consumers, even more so than price. This result was 
also recorded in this study, but only in the MaxDiff exercise. After conducting a consumer acceptance test of ultrapasteurized LFM compared with ultrapasteurized traditional milks, Adhikari et al. (2010) found the increased sweetness of LFM compared with traditional milk to be a driver of disliking for consumers, the opposite finding of this study. Adhikari et al. (2010) did not specifically recruit LFM consumers to participate in their consumer acceptance test, as this study did. LFM is generally sweeter than traditional milk; therefore, as this study proposes, LFM consumers have likely grown accustomed to the increased sweetness of LFM, and that it has become a driver of liking specifically for LFM consumers. However, fluid milk consumers are generally not used to the sweetness of LFM, and would likely score sweeter LFM lower than traditional milk, as seen in the study by Adhikari et al. (2010).

Consumers have stated many reasons for avoiding dairy milk, including animal rights and vegan diets, but concerns about lactose consumption is one of the largest reasons that cause consumers to avoid dairy milk (Zingone et al., 2017). Lactose-free milk is a good alternative for consumers trying to avoid lactose because it provides a rich source of nutrients that are not provided by plant-based dairy alternatives. On average, plant-based milks supply less than half of the protein found in dairy milk (Chalupa-Krebzdak et al., 2018). With the exception of soy milk, plant-based milks are not a source of complete proteins. Additionally, calcium found in dairy milk is much more easily absorbed by the body compared with calcium fortified plant-based milk (Chalupa-Krebzdak et al., 2018). These are examples of the many reasons why plant-based milk alternatives are not recommended as a complete nutritional replacement to dairy milk. When considering that LFM is nutritionally the best alternative to traditional milk for consumers trying to avoid lactose, this makes understanding consumer desires and perceptions of LFM important.

\section{CONCLUSIONS}

Purchasers of LFM are largely comprised of lactose intolerant individuals or individuals who are related to someone lactose intolerant. It is estimated that $70 \%$ of the world's population has some degree of lactose intolerance, making the market potential for LFM is significant. Price is the most important attribute of LFM for purchase decisions. Consumers of LFM view the extended shelf life provided by ultrapasteurization as a benefit. They also prefer half-gallon sized cardboard cartons to other options, including gallon sized plastic jugs. Although label and nutrition claims such as "high protein," "high calcium," and "organic" were the most popular claims found on a package, they were not important when making the overall purchase decision for LFM. High sweet taste is a driver of liking for the majority of LFM consumers. This is important to consider during future product development and consumer testing for LFM consumers. Although they may think of traditional milk as being the "gold standard" target for LFM, reducing sweetness may lead to reduced consumer acceptance. The drivers of disliking for the overall population of LFM consumers are high viscosity and high eggy flavor intensity. Products with these attributes led to decreased acceptability for the majority of LFM consumers. However, it is important to consider that a segment of the population considers these attributes appealing, indicating a market potential for similar high protein, low carbohydrate milks. While this study presents many insights into LFM consumer perceptions and desires, a limitation is that the focus groups and consumer acceptance test were populated entirely with consumers from the Raleigh and Durham area of North Carolina. It is possible that different regional preferences exist between LFM consumers in the United States. Understanding LFM consumer perceptions, drivers of liking, and drivers of disliking can help to guide product development in the dairy industry to better meet the needs of LFM consumers in today's market.

\section{ACKNOWLEDGMENTS}

Funding was provided in part by the National Dairy Council (Rosemont, IL). The authors have not stated any conflicts of interest.

\section{REFERENCES}

Adhikari, K., L. M. Dooley, E. Chambers IV, and N. Bhumiratana. 2010. Sensory characteristics of commercial lactose-free milks manufactured in the United States. Lebensm. Wiss. Technol. 43:113118. https://doi.org/10.1016/j.lwt.2009.06.017.

Al-Omari, B., J. Sim, P. Croft, and M. Frisher. 2017. Generating individual patient preferences for the treatment of osteoarthritis using adaptive choice-based conjoint (ACBC) analysis. Rheumatol. Ther. 4:167-182. https://doi.org/10.1007/s40744-017-0056-4.

Chalupa-Krebzdak, S., C. J. Long, and B. M. Bohrer. 2018. Nutrient density and nutritional value of milk and plant-based milk alternatives. Int. Dairy J. 87:84-92. https://doi.org/10.1016/j.idairyj 2018.07.018.

Chapman, C. N., J. L. Alford, C. Johnson, R. Weidemann, and M. Lahav. 2009. Sawtooth Software Research Paper Series. Accessed April 24, 2020. https://www.sawtoothsoftware.com/support/ technical-papers/adaptive-cbc-papers/cbc-vs-acbc-comparing -results-with-real-product-selection-2009.

Clark, J. E. 1998. Taste and flavour: Their importance in food choice and acceptance. Proc. Nutr. Soc. 57:639-643. https://doi.org/10 $.1079 /$ PNS19980093. 
Dairy Management Inc. 2018. Fluid Milk Retail Report Fluid Milk Retail Report 4-6. Dairy Management Inc., Rosemont, IL.

Harwood, W. S., and M. A. Drake. 2018. Identification and characterization of fluid milk consumer groups. J. Dairy Sci. 101:8860-8874. https://doi.org/10.3168/jds.2018-14855.

Jansson, T., M. R. Clausen, U. K. Sundekilde, N. Eggers, S. Nyegaard, L. B. Larsen, C. Ray, A. Sundgren, H. J. Andersen, and H. C. Bertram. 2014. Lactose-hydrolyzed milk is more prone to chemical changes during storage than conventional ultra-high-temperature (UHT) milk. J. Agric. Food Chem. 62:7886-7896. https://doi.org/ 10.1021/jf501671z.

Jervis, M. G., S. M. Jervis, B. Guthrie, and M. A. Drake. 2014. Determining children's perceptions, opinions and attitudes for sliced sandwich breads. J. Sens. Stud. 29:351-361. https://doi.org/10 $.1111 /$ joss.12116.

Jervis, S. M., J. M. Ennis, and M. A. Drake. 2012. A comparison of adaptive choice-based conjoint and choice-based conjoint to determine key choice attributes of sour cream with limited sample size. J. Sens. Stud. 27:451-462. https://doi.org/10.1111/joss.12009.

Jo, Y., D. M. Benoist, D. M. Barbano, and M. A. Drake. 2018. Flavor and flavor chemistry differences among milks processed by hightemperature, short-time pasteurization or ultra-pasteurization. J. Dairy Sci. 101:3812-3828. https://doi.org/10.3168/jds.2017-14071.

Kano, N., N. Seraku, F. Takahashi, and S. Tsuji. 1984. Attractive quality and must-be quality. J. Japanese Soc. Qual. Control. 14:147-156.

Kim, M. K., K. Lopetcharat, and M. A. Drake. 2013. Influence of packaging information on consumer liking of chocolate milk. J. Dairy Sci. 96:4843-4856. https://doi.org/10.3168/jds.2012-6399.

Kitzinger, J. 1995. Qualitative research: Introducing focus groups. BMJ 311:299-302.https://doi.org/10.1136/bmj.311.7000.299.

Lee, A. P., D. M. Barbano, and M. A. Drake. 2017. The influence of ultra-pasteurization by indirect heating versus direct steam injection on skim and 2\% fat milks. J. Dairy Sci. 100:1688-1701. https: //doi.org/10.3168/jds.2016-11899.

Li, X. E., K. Lopetcharat, and M. Drake. 2014. Extrinsic attributes that influence parents' purchase of chocolate milk for their children. J. Food Sci. 79:S1407-S1415. https://doi.org/10.1111/1750 -3841.12515 .

McCarthy, K. S., K. Lopetcharat, and M. A. Drake. 2017a. Milk fat threshold determination and the effect of milk fat content on consumer preference for fluid milk. J. Dairy Sci. 100:1702-1711. https: //doi.org/10.3168/jds.2016-11417.

McCarthy, K. S., M. Parker, A. Ameerally, S. Drake, and M. Drake. 2017b. Drivers of choice for fluid milk versus plant-based alterna- tives: What are consumer perceptions of fluid milk? J. Dairy Sci 100:6125-6138. https://doi.org/10.3168/jds.2016-12519.

McLean, K. G., D. J. Hanson, S. M. Jervis, and M. A. Drake. 2017. Consumer perception of retail pork bacon attributes using adaptive choice-based conjoint analysis and maximum differential scaling. J. Food Sci. 82:2659-2668. https://doi.org/10.1111/1750-3841 .13934 .

Meilgaard, M. C., G. V. Civilly, and B. T. Carr. 2007 Descriptive analysis techniques. Pages 173-186 in Sensory Evaluation Techniques, 4th ed. CRC Press, Boca Raton, FL.

Messia, M. C., T. Candigliota, and E. Marconi. 2007. Assessment of quality and technological characterization of lactose-hydrolyzed milk. Food Chem. 104:910-917. https://doi.org/10.1016/j .foodchem.2006.12.045.

Nielsen, S. D., D. Zhao, T. T. Le, V. Rauh, J. Sørensen, H. J. Andersen, and L. B. Larsen. 2018. Proteolytic side-activity of lactase preparations. Int. Dairy J. 78:159-168. https://doi.org/10.1016/j .idairyj.2017.12.001.

Oltman, A. E., S. M. Jervis, and M. A. Drake. 2014. Consumer attitudes and preferences for fresh market tomatoes. J. Food Sci. 79:S2091-S2097. https://doi.org/10.1111/1750-3841.12638.

Orme, B. K. 2009. Fine-tuning CBC and adaptive CBC questionnaires. Sawtooth Software Research Paper Series. Accessed April 24, 2020. https://www.sawtoothsoftware.com/support/technical -papers/adaptive-cbc-papers/fine-tuning-cbc-and-adaptive-cbc -questionnaires-2009.

Orme, B. K. 2010. Pages 19-50 in Getting Started with Conjoint Analysis: Strategies for Product Design and Pricing Research. Research Publishers LLC, Madison, WI.

United States Department of Agriculture. November 12, 2019. Economic Research Service. Fluid beverage milk sales quantities by product. Accessed January 7, 2020. https://www.ers.usda.gov/ data-products/dairy-data/documentation/\#Loc8

Zacarias, D. 2015. The Complete Guide to the Kano Model - Folding Burritos. Accessed Dec. 16, 2019. https://foldingburritos.com/ kano-model/.

Zingone, F., C. Bucci, P. Iovino, and C. Ciacci. 2017. Consumption of milk and dairy products: Facts and figures. Nutrition 33:322-325. https://doi.org/10.1016/j.nut.2016.07.019.

\section{ORCIDS}

M. A. Drake (i) https://orcid.org/0000-0002-4744-2493 